\title{
Effect of Glasshouse Maintenance on the Quality of Irradiance Spectrum under Mediterranean Climates
}

\author{
Gonzalo GURREA-YSASI, Vicente BLANCA, Jaime PROHENS, Pascual FERNÁNDEZ-DE-CóRDOVA, \\ Inmaculada FITA-FERNÁNDEZ, Ana FITA, Adrián RODRÍGUEZ-BURRUEZO* \\ Instituto de Conservación y Mejora de la Agrodiversidad Valenciana (COMAV), Universitat Politècnica \\ de València, Camino de Vera 14, 46022 Valencia, Spain \\ *corresponding author: adrodbur@doctor.upv.es
}

Bulletin UASVM Horticulture 75(1) / 2018

Print ISSN 1843-5262, Electronic ISSN 1843-536X

DOI:10.15835/buasvmcn-hort: 001017

\begin{abstract}
Glasshouses in Mediterranean areas are mainly used for experimental or nursery purposes and the production of high value ornamental species. In addition, glasshouses may be covered by dust and other particles in these areas as rainfalls are relatively scarce. Consequently, the quality of photosynthetically active radiation (PAR) may be affected. In the present experiment we evaluated the effect of dirt on the PAR spectrum in glasshouses in Valencia (Spain), compared to glasshouses submitted to suitable maintenance and washing. Photosynthetic Photon Flux Density (PPFD) measurements were done in March 2017 at 13h, and visible, UV-C and near infrared regions were recorded with a portable spectrometer. PPFD maximum values differed depending on the spectral region and glass conditions, with higher values corresponding to the visible region. Thus, clean glass showed values of 609,588 and $423 \mu \mathrm{mol} / \mathrm{m}^{2} \mathrm{~s}$ for $\mathrm{PPFD}_{\mathrm{R}^{\prime}} \mathrm{PPFD}_{\mathrm{G}}$ and $\mathrm{PPFD}_{\mathrm{B}^{\prime}}$, respectively and 436 and $34 \mu \mathrm{mol} / \mathrm{m}^{2} \mathrm{~s}$ for PPFD $\mathrm{IR}_{\mathrm{R}}$ and $\mathrm{PPFD}_{\mathrm{UV}}$. In comparison to clean glass, dirty glass decreased PPFD in all regions, particularly UV and blue region.
\end{abstract}

Keywords: Venlo glasshouse, dust, photosynthetic photon flux density

\section{Introduction}

Despite glasshouses were mainly developed for central and north Europe climates, they are also useful in Mediterranean areas for many activities, e.g. experiments in plant sciences, plant nurseries, production of high value ornamental species. Mediterranean climate is characterized by scarce rains and, on occasions, a considerable density of atmospheric dust. As a consequence, glasshouses transparency and, by extension, the quality of irradiance spectrum and therefore photosynthetic process may be affected (Mortensen and Stromme, 1987). In the present work we evaluated the effect of a suitable maintenance of glasshouses on glass transmittance and the quality of the irradiance spectrum.

\section{Materials and methods}

A comparative study on the transmittance of 4-mm thick glass from Venlo-type glasshouses located at the Universitat Politècnica de València
(Valencia, Spain) was done in two conditions: i) not washed for one year (dirty glass) and ii) recently washed (i.e. clean glass, control), which were compared to the values of incident irradiance on the surface of the glass before passing through the glass. Measurements were done in March 2017 at $13 \mathrm{~h}$ (i.e. solar noon, maximum solar radiation). Photosynthetic Photon Flux Density (PPFD) of UV-C, near infrared regions and the main visible regions were recorded with an Asensetek handheld ALP-01 spectrometer (New Taipei City, Taiwan), covering a range of 380 to $780 \mathrm{~nm}$ wavelength spectrum.

Measurements were done in March as it provides intermediate climatic conditions (including irradiance, light intensity, and also temperature) intermediate to those extreme from november-december (too low irradiance) or summer (too high irradiance and temperature which makes difficult growing plants inside). Plants grown in this experiment within the 
Table 1. Integrated photosynthetic photon flux density values (PPFD, $\mu \mathrm{mol} / \mathrm{m}^{2} \mathrm{~s}$ ) from near infrared (IR), red (R), green (G), blue (B) and UV-C (UV) regions and B/R and R/ IR ratios, corresponding to incident irradiance (on glass surface) and after passing across clean glass and dirty glass

\begin{tabular}{cccc}
\hline & Incident & Clean Glass & Dirty Glass \\
\hline PPFD IR $\left(\mu \mathrm{mol} / \mathrm{m}^{2} \mathrm{~s}\right)$ & 533 & 436 & 424 \\
\hline PPFD R $\left(\mu \mathrm{mol} / \mathrm{m}^{2} \mathrm{~s}\right)$ & 719 & 609 & 585 \\
\hline PPFD G $\left(\mu \mathrm{mol} / \mathrm{m}^{2} \mathrm{~s}\right)$ & 671 & 588 & 559 \\
\hline PPFD B $\left(\mu \mathrm{mol} / \mathrm{m}^{2} \mathrm{~s}\right)$ & 495 & 423 & 393 \\
\hline PPFD UV $\left(\mu \mathrm{mol} / \mathrm{m}^{2} \mathrm{~s}\right)$ & 41 & 34 & 31 \\
\hline PPFD TOTAL $\left(\mu \mathrm{mol} / \mathrm{m}^{2} \mathrm{~s}\right)$ & 1885 & 1620 & 1538 \\
\hline
\end{tabular}

glasshouses were mainly solanaceae like peppers and tomatoes, the most common species in these growing systems.

\section{Results and discussion}

PPFD maximum values were different depending on the spectral region and glass conditions, with higher values corresponding to the visible region. Both glass conditions weakened PAR considerably in terms of total PPFD and PPFD from the different spectral regions, although the lowest values corresponded to dirty glass. Thus, for clean glasses, values were 609, 588 and 423, 436 and $34 \mu \mathrm{mol} / \mathrm{m}^{2} \mathrm{~s}$ for $\mathrm{PPFD}_{\mathrm{R}^{\prime}}, \mathrm{PPFD}_{\mathrm{G}^{\prime}}$ $\mathrm{PPFD}_{\mathrm{B}^{\prime}}, \mathrm{PPFD}_{\mathrm{IR}}$ and $\mathrm{PPFD}_{\mathrm{UV}}$, respectively (Tab. 1). In comparison, dirty glass decreased PPFD in all regions, particularly UV-C and blue region with $\mathrm{PPFD}_{\text {dirty }} / \mathrm{PPFD}_{\text {clean }}$ ratios of 0.91 and 0.93 . R/IR and red and green ratios were also affected although the ratios were $\geq 0.95$.

As it can be shown in Table 1, global PPFD is reduced in $4 \%$ for dirty glasshouse compared with clean one. This is a similar value compared with other authors (Montero et al., 2001; Soriano et al., 2004).

Moreover, our study supply and additional analysis on spectral bands of incoming radiation. It has been found that dust and other particles accumulated on dirt glasshouses provide a selective filtering of the different spectral regions, with a stronger effect on UV-C and blue regions. Our findings indicate that dirtiness on glasshouses modifies the quality of irradiance spectrum, particularly decreasing the UV and blue spectral regions, which may decrease photosynthetic activity and biomass production (Tardieu, 2013), particularly in those species with preference for low-wavelength photons. By contrast, near infrared is less affected, which allows the entrance of thermal radiation to glasshouse to keep temperatures higher than outside. Then, washing is mainly advised to prevent the decrease of the photosynthetic rate.

\section{References}

1. Mortensen LM, Stromme E (1987). Effects of light quality on some greenhouse crops. Sciencia Horticulturae, 33: 2736.

2. Tardieu F (2013). Plant response to environmental conditions: assessing potential production, water demand, and negative effects of water deficit. Frontiers in Physiology, 4:17.

3. Montero JI, Castilla N, Antón A, Hernández J. (2001): Direct and diffuse light transmission of insect-proof screens and plastic films for cladding greenhouses. Acta Horticulturae, 559: 203-209.

4. Soriano T, Montero JI, Sánchez-Guerrero MC, Medrano E, Antón A, Hernández J, Morales MI, Castilla N (2004). Characterisation of Direct Radiation transmission in Asymetrical Multi-span Greenhouses using Scale Models and simulation Models, Journal of Biosystems Engineering, 88(2): 243-253. 